with fever. This case also illustrates the potential benefit in treating hypertension even in acute neurological disorders, although this should always be performed cautiously. ${ }^{6}$

\section{References}

${ }^{1}$ Loggie JM. Systemic hypertension in children and adolescents. Pediatr Clin North Am 1971;18:1273-310.

2 Wilkins RH, Rengachary SS. Neurosurgery. New York: McGraw-Hill, 1985.

${ }^{3}$ Nagao S, Sunami N, Tsutsui $T$, et al. Acute intracranial hypertension and brain-stem blood flow. J Neurosurg 1984;60:566-71.
4 Evans A. Cerebral ischaemia as a factor in the vasomotor response to increased intracranial pressure. Tex Med 1967;63:84-90.

5 Scheld WM. Pathophysiological correlates in bacterial meningitis. Journal of Infection 1981;3 (Supp 1):5-9.

${ }^{6}$ Eden OB, Sills JA, Brown JK. Hypertension in acute neurological diseases in childhood. Dev Med Child Neurol 1977;19:437-45.

Correspondence to Dr J Gillis, Intensive Care Unit, Royal Alexandra Hospital for Children, Pyrmont Bridge Road, Camperdown, New South Wales, 2050, Australia.

Received 1 August 1986

\title{
Phosphatidylglycerol in tracheal aspirates for diagnosis of hyaline membrane disease
}

\author{
J FRANCOUAL, J F MAGNY, J C ROPERT, M DEHAN, AND R LELUC
}

Laboratoire de Biochimie and Service de Réanimation Néonatale, Hôpital Antoine Béclère, Clamart, France

SUMMARY Lecithin:sphingomyelin ratio and phosphatidylglycerol were determined by a rapid, simple method in tracheal aspirates obtained from 132 newborn infants with respiratory diseases, sixty five of whom developed hyaline membrane disease. Phosphatidylglycerol determination was more sensitive $(97 \%)$ than lecithin:sphingomyelin ratio, but their specificities were similar $(76 \%)$.

A deficiency in the pulmonary surfactant is believed to cause hyaline membrane disease in newborn infants. Pulmonary maturity has been assessed by the analysis of the phospholipids in the hypopharyngeal ${ }^{1}$ and tracheal ${ }^{2}$ aspirates of newborn infants. The most widely used test is the lecithin: sphingomyelin ratio described by Gluck et al, ${ }^{3}$ but this method is time consuming and affected by contamination of the specimen with blood or meconium.

As a consequence, several investigators have suggested that other phospholipids from surfactant and particularly phosphatidylglycerol (PG) should be studied. ${ }^{4} \mathrm{PG}$ is synthesised almost exclusively by lung alveolar cells so that there is no interference in assays by blood or meconium. Both one and two dimensional thin layer chromatography are commonly used to analyse PG. These methods are time consuming, however, and require extensive laboratory technician training.

In 1983. Garite et al described a new, rapid, simple, and reliable method to determine $P G$ in amniotic fluid by a semiquantitative immunological slide agglutination test. ${ }^{5} \mathrm{~A}$ complete assay can be performed in about 30 minutes.

We have applied and compared this test to the lecithin:sphingomyelin in the tracheal aspirate.

\section{Patients and methods}

Tracheal aspirates were obtained from 132 infants who were admitted to the intensive care unit for respiratory disease. Of these, 65 were diagnosed as having hyaline membrane disease after satisfying clinical and $x$ ray criteria. The other 67 infants had other respiratory diseases-namely, transient tachypnoea of the newborn (30 cases), congenital pneumonia (six), amniotic fluid aspiration syndrome (11), and other respiratory diseases (20). The gestational ages of the infants ranged from 26 to 42 weeks (mean 33 weeks) and their birth weights from 645 to $4700 \mathrm{~g}$ (mean $2160 \mathrm{~g}$ ). Samples were obtained during the first 24 hours after birth.

The lecithin:sphingomyelin ratio was determined using the method of Gluck $e t \mathrm{al}^{3}$ and PG testing by Amniostat-FLM ${ }^{5}$ were performed on all samples. A lecithin:sphingomyelin ratio $\geqslant 2.0$ and a $P G \geqslant++$ or $2 \mu \mathrm{g} / \mathrm{ml}$ were interpreted as being 'positive' and as indicating fetal lung maturity and a lecithin:sphingomyelin ratio $<2$ and $\mathrm{PG}<++$ were interpreted as being 'negative'. ${ }^{2-5}$

\section{Results}

The Table shows the results of the lecithin:sphin- 
Table Determination of lecithin:sphingomyelin $(L: S)$ ratio and phosphatidylglycerol $(P G)$ in tracheal aspirates obtained from 132 newborn infants with respiratory diseases

\begin{tabular}{|c|c|c|c|c|c|}
\hline & \multirow[t]{2}{*}{$(n=)$} & \multicolumn{4}{|c|}{ Results of determinations } \\
\hline & & $L: S$ and $P G$ negative & L:S and PG positive & $\begin{array}{l}L: S \text { negative and } \\
P G \text { positive }\end{array}$ & $\begin{array}{l}L: S \text { positive and } \\
P G \text { negative }\end{array}$ \\
\hline Infants with hyaline membrane disease & $(65)$ & 59 & 2 & 0 & 4 \\
\hline Infants without hyaline membrane disease: & (67) & & & & \\
\hline Transient tachypnoea & (30) & 2 & 25 & 2 & 1 \\
\hline Congenital pneumonia & (6) & 1 & 4 & - & 1 \\
\hline Amniotic fluid aspiration syndrome & (11) & 1 & 8 & 1 & 1 \\
\hline Other respiratory diseases & (20) & 5 & 6 & 4 & 5 \\
\hline Total & $(67)$ & 9 & 43 & 7 & 8 \\
\hline
\end{tabular}

gomyelin and PG determination in tracheal aspirates of the 132 newborn infants with respiratory diseases.

For 59 of the 65 newborn infants $(91 \%)$ who developed hyaline membrane disease, the two tests correlated well with the criteria for hyaline membrane disease, but for six $(9 \%)$ the results showed no correlation. In four of these six cases the lecithin:sphingomyelin ratio was $\geqslant 2$ but the $P G$ was absent, and for the other two cases both tests indicated fetal lung maturity.

For the 67 newborn infants who did not have hyaline membrane disease, both biochemical tests predicted pulmonary maturity for 43 of them $(64 \%)$, but for the 24 others $(36 \%)$ the results showed no correlation. This lack of correlation was particularly noticeable in these cases with other respiratory diseases (14 of 20), particularly when their gestational ages were less than 30 weeks $(80 \%$ of the cases). The lack of correlation was not so pronounced, however, in the cases with transient tachypnoea (five of 30), congenital pneumonia (two of six), and amniotic fluid aspiration syndrome (three of 11).

\section{Discussion}

In most cases (102 of $132(77 \%))$ a good correlation was observed between the results of laboratory tests and the clinical and $x$ ray criteria for hyaline membrane disease.

The correlation was better, however, for the newborn infants who had hyaline membrane disease $(91 \%)$. James et $a l^{6}$ reported that for babies who did not have hyaline membrane disease, and in particular transient tachypnoea, congenital pneumonia, or amniotic fluid syndrome, the determination of phospholipids in tracheal or gastric aspiration was of doubtful importance. In our study this was observed for other respiratory diseases, in particular when the gestational age of the newborn was very low, but not for transient tachypnoea, congenital pneumonia, or amniotic fluid aspiration syndrome.
For the results that did not correlate $(23 \%)$, in 11 infants $(8 \%)$ both biochemical tests differed from the clinical diagnosis. The specificities of lecithin: sphingomyelin ratio and PG determination were similar $(76 \%$ and $77 \%$, respectively). In 19 cases $(14 \%)$ there was no correlation between the two tests, but the PG determination was more sensitive $(97 \%)$ than the lecithin:sphingomyelin ratio $(88 \%)$ and the results were unaffected by blood or meconium contamination.

In conclusion, the high sensitivity, specificity, rapidity, and simplicity of this assay makes PG determination a useful method for assessing the presence of PG in tracheal aspirates in newborn infants for diagnosis of hyaline membrane disease.

\section{References}

1 Barr PA, Jenkins PA, Baum JD. Lecithin:sphingomyelin ratio in hypopharyngeal aspirate of newborn infants. Arch Dis Child 1975:50:856-61.

2 Dehan M. Ropert JC, Francoual J, et al. Diagnostic biologique de la maladie des membranes hyalines et de l'inhalation de liquide amniotique. Arch Fr Pédiatr 1979;36:886-93.

${ }^{3}$ Gluck L, Kulovitch MV, Borer RC, Brenner PH, Anderson GG, Spellacy WN. Diagnosis of respiratory distress syndrome by amniocentesis. Am J Obstet Gynecol 1971; 109:440-5.

${ }^{4}$ Hallman M, Feldman BH, Kirkpatrick E, Gluck L. Absence of phosphatidylglycerol (PG) in respiratory distress syndrome in the newborn. Study of the minor surfactant phospholipids in newborns. Pediatr Res 1977;11:714-20.

5 Garite TJ, Yabusaki KK. Moberg LJ, et al. A new rapid slide agglutination test of amniotic fluid phosphatidylglycerol:laboratory and clinical correlation. Am J Obstet Gynecol 1983;147:681-6.

6 James DK, Chiswick ML, Harkes A, Williams M, Hallworth J. Non-specificity of surfactant deficiency in neonatal respiratory disorders. Br Med J 1984;288:1635-7.

Correspondence to $\mathrm{Dr} \mathbf{J}$ Francoual, Laboratoire de Biochimic, Hôpital Antoine Béclère, 157 rue de la Porte de Trivaux, 92141 Clamart, France.

Received 26 August 1986 